H.C. $\$ 2.00 ;$ 50

\title{
MOUND LABORATORY PROGRESS REPORT FOR NOVEMBER, 1965
}
J. F. Eichelberger
G. R. Grove
L. V. Jones

Date: November 22, 1965

Issued: July 20, 1966
The Mound Laboratory Progress Report, issued monthly, is intended to The Mound Laboratory Progres of current technical interest in research be a means of reporting items issue this report as soon as possible and development programs. To issue this replimited; and since this is after the end of the month, editorial work is limited; and since this is an informal progress report, the results and data presented are prelimi nary and subject to change.

These reports are not intended to constitute publication in any sense These reports are not intended to constill be submitted for publication in regular professional journals or will be published in the form of MLM topical reports.

The previous reports in this series are:
MLM- 1300

MLM- 1299

MLM- 1287

MLM- 1274

MLM- 1268

MLM- 1266
MLM- 1254

MLM- 1250

MLM- 1245

MLM- 1238

MLM-123

MLM- 1227
This document is PUBLICLY RELEASABLE byentaknew Authorying Oticia

Date: \section{然}

\section{MONSANTO RESEARCH CORPORATION}

A SUBSIDIARY OF MONSANTO COMPANY

\author{
MOUND LABORATORY \\ MIAMISBURG, OHIO OPERATED FOR
}

\section{UNITED STATES ATOMIC ENERGY COMMISSION}

U.S. GOVERNMENT CONTRACT NO. AT.33-1.GEN-53

\section{LEGAL NOTICE}

A This report was prepared as an account of Governg on behalf of the Commission: States, nor the Commission, nor any person acting on betal of A. Makes any warranty or representation, expressed or racy, completeness, or usefulness of the information contained in this report may not infringe of any information, apparatus, method, or process disclosed in this report may not infringe privglely owned rights; or

B. B. Assumes any liabilities with respect or process disclosed in this report. use of any information, appan "person acting on behalf of the Commission" Includes any emAs used in the a the commission, or employee of such contractor, to the extent that ployee or contractor of the Cor the Commission, or employee of such contractor prepares, such employee or conis employment or contract disseminates, or provid a contractor. 


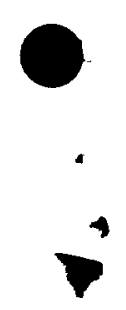




\section{DISCLAIMER}

This report was prepared as an account of work sponsored by an agency of the United States Government. Neither the United States Government nor any agency Thereof, nor any of their employees, makes any warranty, express or implied, or assumes any legal liability or responsibility for the accuracy, completeness, or usefulness of any information, apparatus, product, or process disclosed, or represents that its use would not infringe privately owned rights. Reference herein to any specific commercial product, process, or service by trade name, trademark, manufacturer, or otherwise does not necessarily constitute or imply its endorsement, recommendation, or favoring by the United States Government or any agency thereof. The views and opinions of authors expressed herein do not necessarily state or reflect those of the United States Government or any agency thereof. 


\section{DISCLAIMER}

Portions of this document may be illegible in electronic image products. Images are produced from the best available original document. 


\section{TABLE OF CONTENTS}

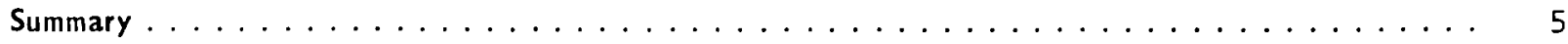

Radioelements

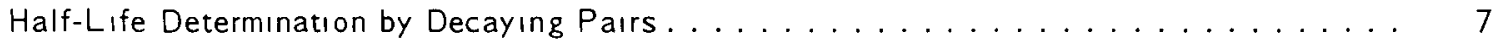

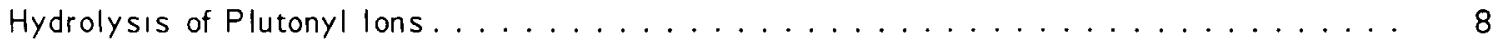

Isotope Separation and Purification

Carbon Isotope Separation . . . . . . . . . . . . . . . . . . 10

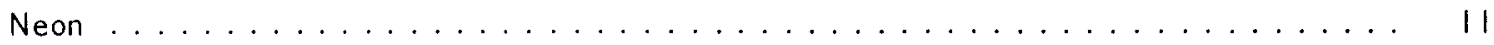

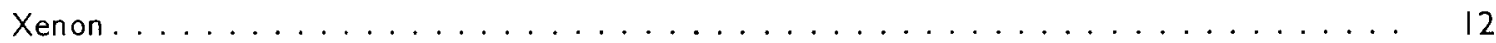

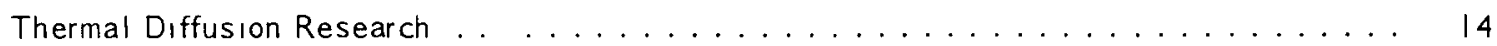

Helıum Research.............................. 23 


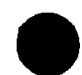

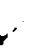




\section{SUMMARY}

\section{RADIOELEMENTS}

Half-Life Determination by Decaying Pairs The determination of the half-life of polonım-210 by alphacounting has again been discontınued because of instrument malfunction. After 140 days and 36 observations, the half-lıfe of polonium- 210 was found to be $138.48 \pm 0.16$ days by the method of decaying pairs, $139.20 \pm 0.34$ days by the varıational method, and $139.19+0.42$ days by the general method. The advantage of the decaying pair method in accuracy and precision is clearly evident after only one half-life period. A new series of measurements is being started in an effort to determine the limits of precision and the optımum conditions for half-life determination by the three methods of computation.

Hydrolysis of Plutonyl Ions Solid plutonium(VI) nitrate, which has been prepared successfully in small amounts, was prepared on a larger scale to improve the yield and to obtain single crystals of the product for single-crystal x-ray investigations. Samples of the product obtained from $10 \mathrm{~g}$ of plutonium-239 metal were used to obtain powder pictures whose patterns appear to be isostructural with powder patterns of uranyl nitrate hexahydrate

\section{ISOTOPE SEPARATION AND PURIFICATION}

\section{Carbon Is otope Separation}

Chemical Exchange Two reactions were performed with monoethanolamine in isopropanol. A maxımum separation factor of 349 was obtaıned. A similar reaction run using a mixed solvent of equal parts of isopropanol and methanol produced a maximum separation factor of 248 .

Neon Static tests run on the three-column neon tube bundle showed a maximum separation factor of 160 at a pressure of 1000 torr for one 12-ft column.

Xenon

Thermal Diffusion The xenon six-stage tube bundle cascade has enriched xenon-124 to $28 \%$ and

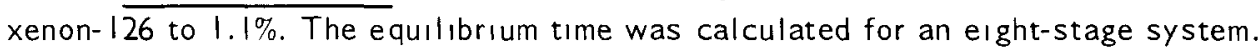

\section{Thermal Diffusion Research}

Transport Coefficients Flow experiments for $\mathrm{Ne}^{20}-\mathrm{Ne}^{22}$ separation in the 6-ft (183-cm) experimental column are being repeated to elımınate the possible influence of end effects. Statıc separatıon data taken in preparation for the flow experiments agree with data taken previously.

Flow separation data for $\mathrm{He}^{3}-\mathrm{He}^{4}$ in one of the $12-\mathrm{ft}(366-\mathrm{cm})$ experimental columns were analyzed and transport coefficients were obtaıned. The initial transport coefficient $H^{\prime}$ agreed with theory; however, remixıng coefficients showed large deviatıons.

Transport Properties Thermal diffusion ratios for various $\mathrm{He}^{3}-\mathrm{He}^{4}$ mixtures were calculated using four different approximatıons. The potentıal parameter $\alpha$ in the Modified Buckıngham Potentıal was also 
varied to test the sensitivity of $\left[k_{T}\right]_{m}$ to the repulsive portion of the potential. The results indicate that Trennschaukel experiments should easily be accurate enough to yield information about the intermolecular potential. Furthermore, it will probably be necessary to use higher approximations for $\left[k_{T}\right]_{m}$ when accurate experımental data are avaılable for comparıson.

There is some indication that the intermolecular forces, or more specifically, the interatomic forces, for helıum- 4 are different from those for helıum- 3 or that there are rather large errors in the theoretical calculations of the transport propertıes of helıum-3. In an effort to obtain more information concerning the interatomic forces, the spectroscopic data for the $\mathrm{He}_{2}$ molecule were examıned Using the standard formulae for the relations between the molecular constants for isotopic molecules, the spectra of $\mathrm{He}_{2}^{3}$ and $\mathrm{He}_{2}^{4}$ give no indication of a difference in the interatomic forces.

\section{Helium Research}

Vapor Pressure Thermometry Thermomolecular pressure corrections are necessary for precise vapor pressure thermometry In the investigation of these corrections both experimentally and theoretically it has become clear that the correction depends on the material of the tube surface In previous reports an equation similar to the Weber-Schmidt expression for thermomolecular pressure has been developed. In this development, one of the parameters that appears is the fraction $f$ of molecules which give up all their tangential momentum in collisions with the tube wall. It will be shown that a variation of this parameter can account for the difference between measurements on staınless steel tubes and the thermomolecular pressure given by the Weber-Schmidt equation. 


\section{RADIOELEMENTS}

Basic and applied research is being conducted on a number of radioelements to determine their physical properties, to develop analytical techniques, and to study the basic radiochemistry involved. Of particular interest are alpha emitters, their decay chains, their isotopes, and their chemical homologs.

\section{HALF-LIFE DETERMINATION BY DECAYING PAIRS}

The determınation of the half-lıfe of polonıum-210 by alpha-countıng' has again been discontınued because of instrument malfunction. It was found necessary to replace a critical vacuum tube in the proportional counter, and this replacement resulted in a substantial change in the resolution time of the instrument

However, counting appears to have progressed normally enough durıng the first 140 days to permit a comparison between the decaying pair method' on the one hand (Table I) and the variational and general methods ${ }^{2}$ on the other (Table 2). In addition, the resolution time of the counter was determined for each sample by the known half-life method, ${ }^{3}$ based on the calorimetric value of $138.3763 \pm 0.0017$ days for the half-life of polonium-2104 (Table 3).

A comparıson of Tables I and 2 Illustrates the advantage of the decayıng paır method of half-lıfe determInation over the variational and general methods. Both the probable error and the absolute error are significantly improved when the uncertainty in the resolution time is eliminated by treating the samples in pairs.

Simılarly, when the half-life can be treated as exact, the determınation of the resolution time is greatly facilitated and its probable error is reduced (Table 3). However, polonium-210 is unique in having a halflife which is known with such accuracy and precision; the half-lives of most radioisotopes suitable for use in the known half-life method usually have uncertainties several orders of magnitude higher.

\section{Table I}

\section{HALF-LIFE OF POLONIUM-210 BY DECAYING PAIRS ${ }^{a}$}

\begin{tabular}{|c|c|c|c|c|}
\hline Pair & Ratio & $\begin{array}{l}\text { Half-Life } \\
\text { (days) }\end{array}$ & $\begin{array}{c}\text { Probable Error } \\
\text { (days) }\end{array}$ & $\begin{array}{c}\text { Absolute Error }{ }^{b} \\
\text { (days) }\end{array}$ \\
\hline $1-2$ & 072 & 13894 & $\pm 0 \quad 14$ & +057 \\
\hline $1-3$ & 062 & 13843 & +015 & +005 \\
\hline $1-4$ & 039 & 13838 & $\pm 0 \quad 14$ & 000 \\
\hline $2-3$ & 086 & 13700 & $\pm 0 \quad 48$ & -1.38 \\
\hline $2-4$ & 054 & 13788 & \pm 027 & -050 \\
\hline $3-4$ & 063 & 13822 & \pm 049 & -015 \\
\hline \multicolumn{2}{|c|}{ Weighted Average } & 13848 & +016 & +011 \\
\hline
\end{tabular}

TMLM-1254 P 7

${ }^{2} \mathrm{H} . W$ Kirby and J. Z Braun, MLM-1263 (January 28, 1966).

${ }^{3} \mathrm{H}$. W. Kirby and J.Z Braun MLM-1202 (November 27, 1964)

$4 M L M-1209$, p 12. 
Table 2

HALF-LIFE OF POLONIUM-210 BY THE VARIATIONAL AND GENERAL METHODS ${ }^{a}$

\begin{tabular}{ccc} 
Sample & $\begin{array}{c}\text { Variational Method Half-Life } \\
\text { (days) }\end{array}$ & $\begin{array}{c}\text { General Method Half-Life } \\
\text { (days) }\end{array}$ \\
\hline 1 & $139.42 \pm 0.57$ & $139.44 \pm 0.59$ \\
2 & $138.81 \pm 0.72$ & $138.81 \pm 0.74$ \\
3 & $138.32 \pm 1.10$ & $138.30 \pm 1.12$ \\
4 & $143.59 \pm 2.35$ & $143.98 \pm 2.65$ \\
Weighted Average & $139.20 \pm 0.34$ & $139.19 \pm 0.42$ \\
a 36 observations over 140 days & &
\end{tabular}

Table 3

RESOLUTION TIME OF A PROPORTIONAL COUNTER BY THE VARIATIONAL, GENERAL, AND KNOWN HALF-LIFE METHODS

\begin{tabular}{cccc} 
Sample & $\begin{array}{c}\text { Variational Method } \\
\text { Resolution Time } \\
\left(\min \times 10^{7}\right)\end{array}$ & $\begin{array}{c}\text { General Method } \\
\text { Resolution Time } \\
\left(\min \times 10^{7}\right)\end{array}$ & $\begin{array}{c}\text { Known Half-Life Method } \\
\text { Resolution Time } \\
\left(\min \times 10^{7}\right)\end{array}$ \\
\hline 1 & $1.06 \pm 0.13$ & $1.08 \pm 0.14$ & $1.33 \pm 0.01$ \\
2 & $1.18 \pm 0.12$ & $1.22 \pm 0.12$ & $1.29 \pm 0.01$ \\
3 & $1.29 \pm 0.16$ & $1.34 \pm 0.16$ & $1.33 \pm 0.01$ \\
4 & $0.80 \pm 0.21$ & $0.82 \pm 0.24$ & $1.33 \pm 0.02$ \\
Weighted Average & $1.12 \pm 0.07$ & $1.16 \pm 0.08$ & $1.31 \pm 0.03$ \\
& & &
\end{tabular}

A new series of measurements will be started in the near future in an effort to determine the limits of precision and the optimum conditions for half-life determination by the three methods of computation.

\section{HYDROLYSIS OF PLUTONYL IONS}

Solid plutonium(VI) nitrate has been prepared successfully. However, only $1.3 \mathrm{~g}$ of product (approximately $39 \%$ yield) was obtained. The product was a brown powder which readily dissolved in nitric acid. The preparation was repeated on a larger scale to improve the yield and to try to obtain single crystals of the product for single-crystal $x$-ray investigations.

In this procedure, $10 \mathrm{~g}$ of plutonium-239 metal was dissolved in $6 \mathrm{~N} \mathrm{HCl}$. After dissolution of the metal, the $\mathrm{HCl}$ solution was evaporated. However, in contrast to the method used in the previous preparation, the 
solution was not evaporated to dryness. Before the solution had completely evaporated, IN $\mathrm{HNO}_{3}$ was added to bring the volume to approximately $75 \mathrm{cc}$. This evaporation and addition step was performed three tımes, until no chloride was present in the resultıng solution $A$ 15\% excess of silver(II) oxide, based on the equivalents of plutonium(IV) in solution, was added to the solution in four equal portions. This reagent quantitatively oxıdızed the plutonıum(IV) to plutonıum(VI), as determıned by spectrophotometric technıques. The excess silver was then precipitated with $6 \mathrm{~N} \mathrm{HCl}$; the precipitate was allowed to digest overnight, and the solution was then filtered.

The anion exchange step, which had been previously used to remove chloride, was elıminated. The solution, after filterıng, was placed in an evacuated desiccator which contained $\mathrm{KOH}$ and $\mathrm{P}_{2} \mathrm{O}_{5}$ and was slowly evaporated. The complete evaporation took four days. After the third day, large single crystals of plutonyl nitrate were seen on the bottom of the beaker. After the solution had completely evaporated, the product was washed with chloroform.

It has been reported ${ }^{5}$ that plutonyl nitrate hexahydrate is insoluble in chloroform. However, when the chloroform solution used to wash the solid product was allowed to evaporate, single crystals were again found

The solıd product obtained has been divided into three samples. These are: (1) the large crystals grown from the original solution, (2) the crystallites left on the sides of the beaker, formed as the volume of solution decreased, and (3) the crystals grown from the chloroform solution. These samples are beıng subjected to chemical and $\mathrm{x}$-ray analysis.

As of this date, no chemical analysis results have been obtained. However, x-ray powder pictures have been taken of samples 1 and 2 . The powder picture of sample 2 compared very favorably with a powder picture taken of uranyl nitrate hexahydrate. The two patterns appear isostructural. If this observation proves to be correct, the complete structural determınation of plutonyl nitrate hexahydrate will be greatly simplified.

\footnotetext{
5M. Y. Krevinskaya, V. D. Nikol'skı, B. G. Pozharskıl and Y. Y. Zastenker, Radıokhımıya, I, No. 5, 562-6 (1959).
} 


\section{ISOTOPE SEPARATION AND PURIFICATION}

Under the sponsorship of the Division of Research. Mound Laboratory is responsible for furnishing material to be used in the physical sciences to further the progress of science and technology in the public interest After recovery, purification and concentration, research quantities of isotopes are furnished to installations for research programs in the physical sciences Purified helium-3 and the isotopes of other noble gases and carbon-13 are available for distribution in research quantities Methods of separation and purification are being studied

\section{CARBON ISOTOPE SEPARATION}

Chemical Exchange Several experiments involving changes in concentration and solvents in monoethanolamıne solutions were performed in the chemical exchange system for the study of carbon- 13 separation Two reactions were performed using a monoethanolamıne solution in isopropanol. The first run was made using a $09 \mathrm{M}$ solution and no major precipitation problems occurred in the reactor The maximum separation factor obtaıned in this run was 348 , but the plot of the separation factor as a function of tıme indıcated that the results were erratic

In the second reaction run, a solution of $093 \mathrm{M}$ monoethanolamine in isopropanol was used Again, precipıtation was not observed in the reactor The maxımum separation factor achieved was 349 , but the data were erratic The two curves are shown in Figure $I$ for comparison

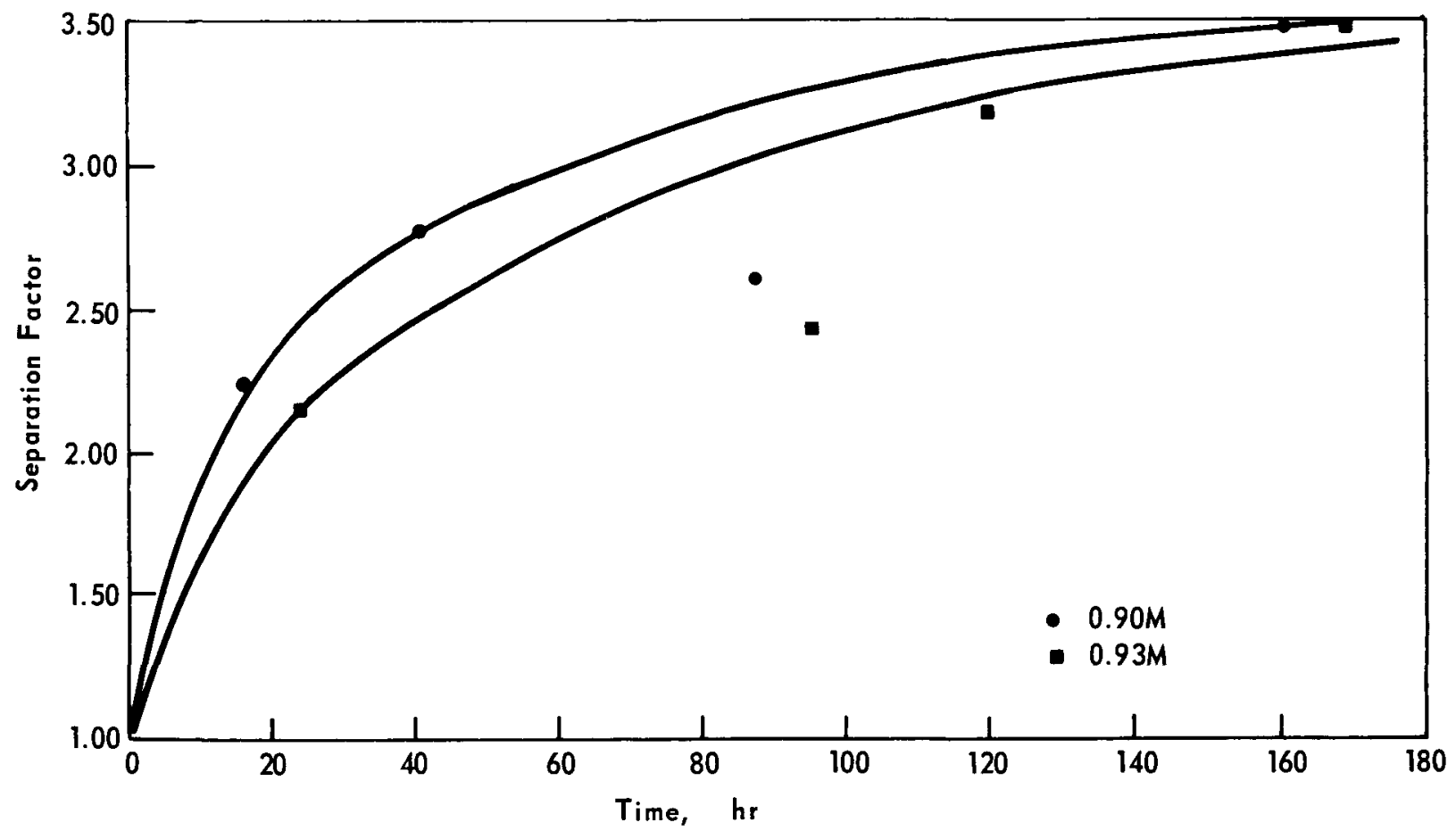

Figure 1. Separation Factor as a Function of Time for Monoethanolamine in Isopropanol. 
One further experıment was performed. A IM solution of monoethanolamıne was prepared usıng a mıxed solvent of isopropanol and methanol in equal portions. The purpose of this experiment was to determine the effect of changing the solvent character on separation without greatly changing the decomposition temperature The results showed a maximum separation factor of 289 Figure 2 illustrates the inconsistency of the results

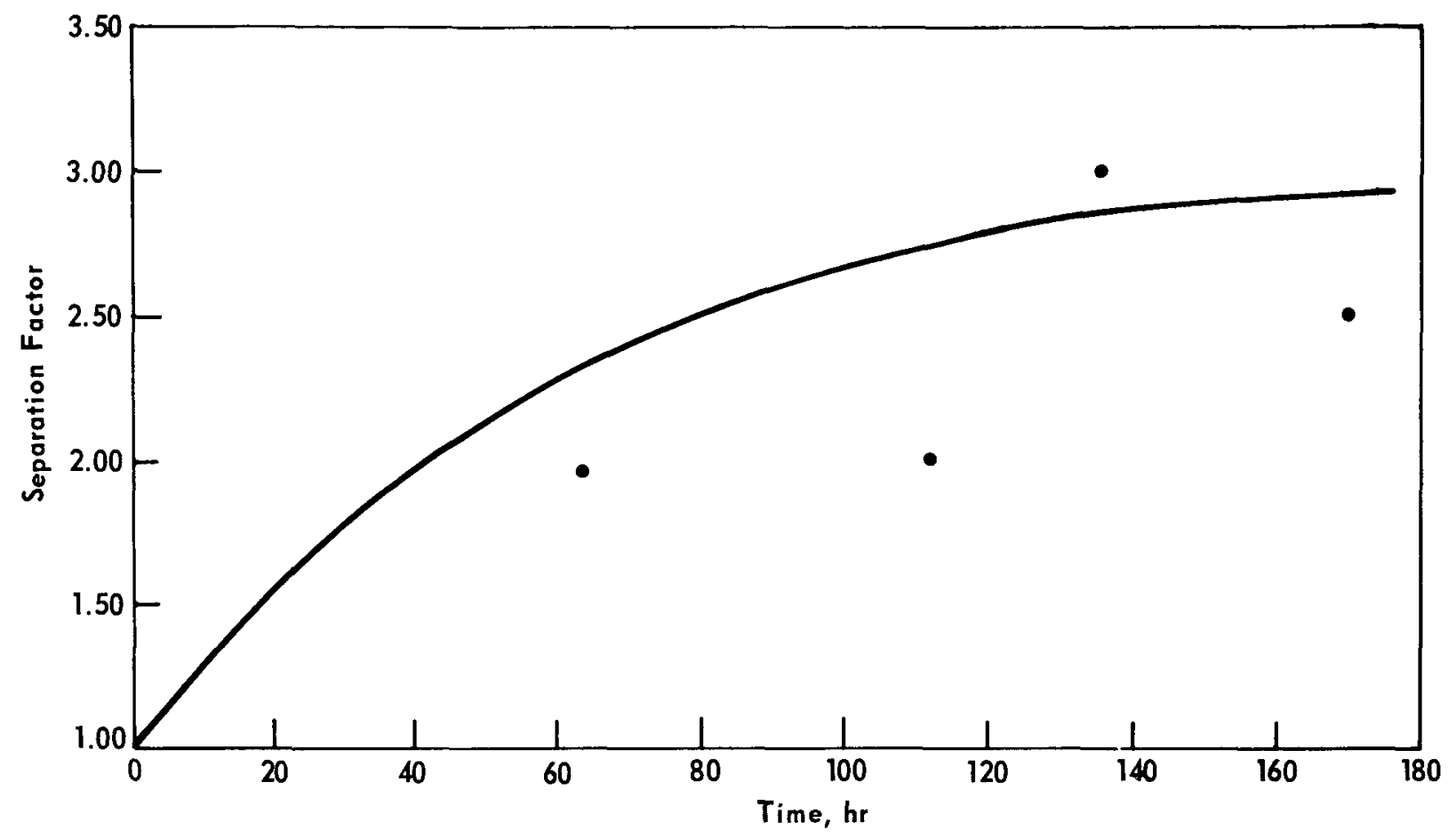

Figure 2 Separation Factor as a Function of Time for Monoethanolamine in Isopropanol-Methanol Mixture

An analysis of an amine from a previous reaction run in which a maximum separatıon factor of 300 was obtained showed that the decomposition of the carbamate is still far from complete It must be remembered, however, that the amine sample was taken from the system at the completion of the reaction, and the analysis can be compared only with the separation factor of 248 obtained at that same time The problems with inconsistent results may be caused by inconsistent decomposition in the boiler. To determine the effect of changing the solvent character on the separation factor, a sample of the amine will be analyzed each time a sample of carbon dioxide is withdrawn

\section{NEON}

A prelıminary test with the new 36-ft, three-column neon tube bundle cascade was completed The test consisted of a static experiment to obtain data for a plot of the logarithm of the static separation factor $q_{s}$ as a function of pressure The data for seven operating pressures are shown in Figure 3 ( $L$ is the length of the column) The pressure at which maximum static separation will occur was tound to be 1000 torr 


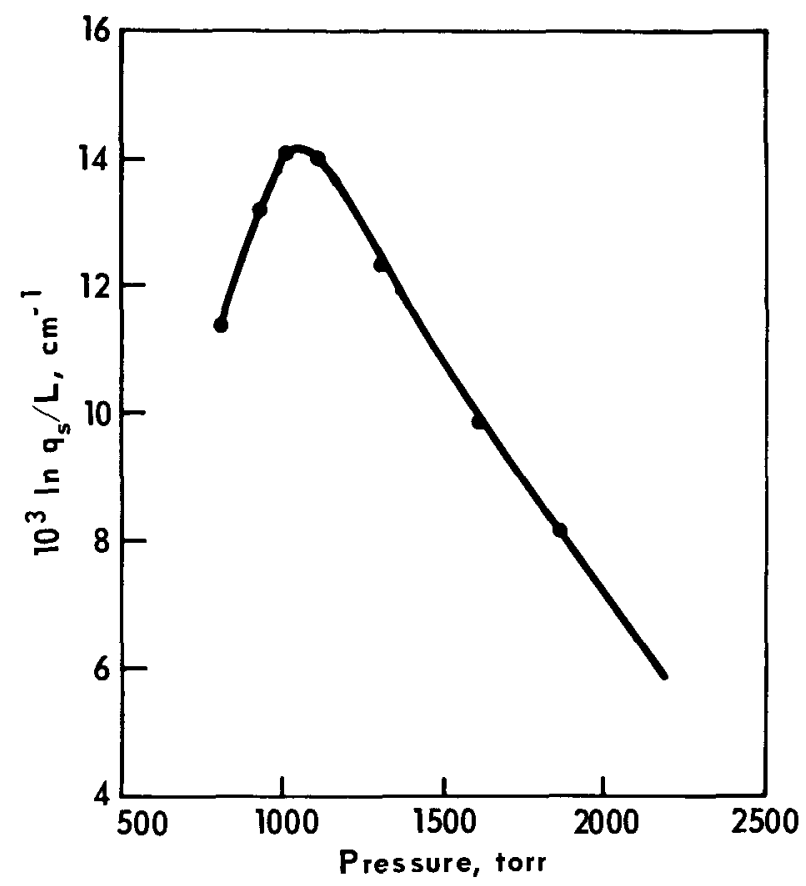

Figure 3. Separation as a Function of Pressure for Column 2 of the 36-ft Tube Bundle.

Using the $2500 \mathrm{ml}$ of neon-2I enriched to $10 \%$ accumulated from the $96-\mathrm{ft}$ cascade as initial feed material, the tube bundle was put in operation At an operatıng heater temperature of $750^{\circ} \mathrm{K}$, a pressure of 817 torr was reached. After the system equilibrated for three days, the concentrations shown in Figure 4 were obtained. At a pressure of 817 torr, the column is operatıng at $37 \%$ of its separatıng capacity; accordingly, a higher neon-2I concentration than $22.4 \%$ is expected when the maximum separation pressure of 1000 torr is reached. At the present draw-off rate of $10 \%$ neon- 21 from the $96-\mathrm{ft}$ cascade, three weeks are needed to accumulate enough gas to fill the bundle to 1000 torr. The bundle will then be operated at this pressure. Highly enriched neon-20 and neon-22 will be removed from the ends of the bundle at small rates and the column will be replenıshed with more gas containing $10 \%$ neon- 21 , keepıng the system pressure at 1000 torr. Continual operation of the bundle in this manner will yield highly enriched neon-2 1 at the middle of the system.

\section{XENON}

Thermal Diffusion Using fission product xenon as feed in an eight-column, eight-stage, hot-wire thermal diffusion cascade with a modified Trennschaukel gas circulating system for interstage transport, xenon136 was enriched to $70 \%$. A sufficient amount of gas of this concentration was accumulated for use as intermediate feed for a second pass. This second pass is expected to enrich the xenon- 136 above $90 \%$.

Natural xenon is being used as feed in a 24-column, six-stage thermal diffusion concentric tube cascade to enrich the light mass fraction. Table 4 shows the isotopic comparison of the product with the feed.

With a Veeco leak in the product line the draw-off rate was set at $5 \mathrm{ml} / \mathrm{hr}$, the calculated value for $2.5 \%$ xenon- 124 product draw-off. Sample analyses showed the results as presented in Table 5. 


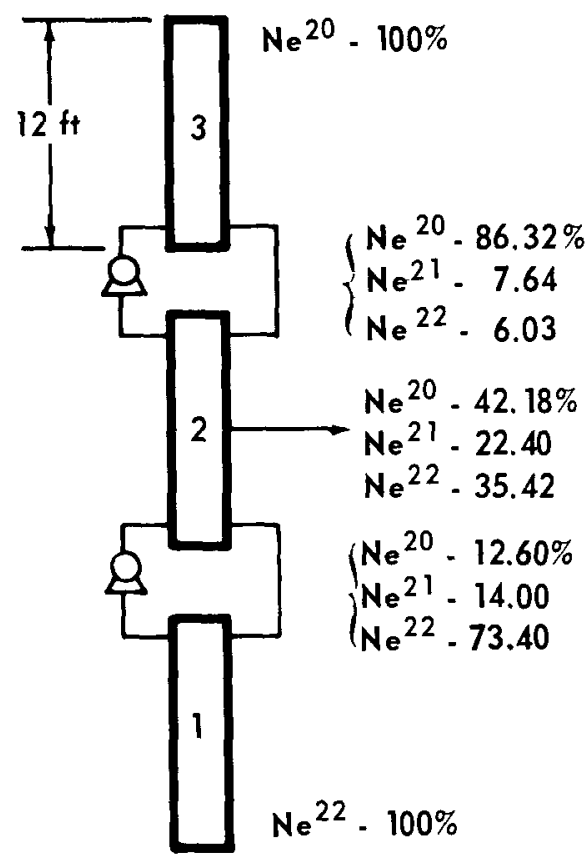

Figure 4. Concentrations in the Cascade after 3 Days of Static Operation at a Pressure of 817 torr.

Table 4

\section{COMPARISON OF ENRICHED LIGHT XENON FRACTION WITH NATURAL XENON}

\begin{tabular}{lcc}
$\begin{array}{c}\text { Xenon } \\
\text { Isotope }\end{array}$ & $\begin{array}{c}\text { Natural Xenon } \\
\text { (mole \%) }\end{array}$ & $\begin{array}{c}\text { Enriched } \\
\text { Xenon- 124 } \\
(\text { mole \%) }\end{array}$ \\
\hline 124 & 0096 & 283 \\
126 & 0090 & 111 \\
128 & 192 & 821 \\
129 & 2644 & 6207 \\
130 & 408 & 491 \\
131 & 2118 & 1256 \\
132 & 2689 & 760 \\
134 & 1044 & 061 \\
136 & 887 & 011
\end{tabular}

The product draw-off rate was reduced to $4 \mathrm{ml} / \mathrm{hr}$ as a precaution.

Figure 5 shows the feed changes, draw-offs and increase in xenon- 124 concentration for the last contınuous run. 
Table 5

CHANGES IN COMPOSITION DURING DRAW-OFF

\begin{tabular}{lcc} 
Isotope & \multicolumn{2}{c}{ Concentration (mole \%) } \\
\cline { 2 - 3 } of Start & $\begin{array}{c}28 \text { Hours after } \\
\text { Draw-off Was Started }\end{array}$ \\
\hline Xenon-124 & 2.75 & 2.58 \\
Xenon-126 & 1.08 & 1.04
\end{tabular}

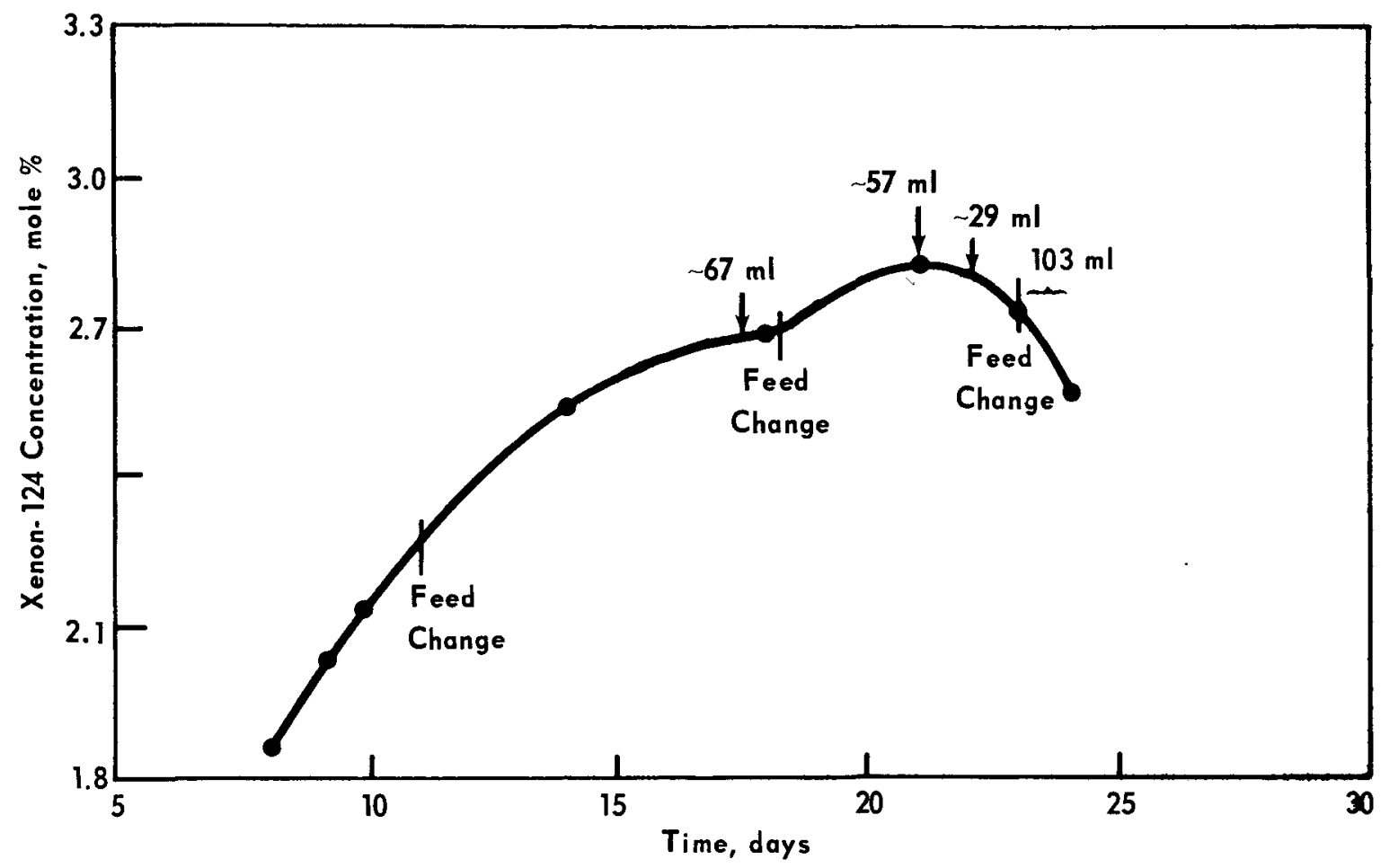

Figure 5. Xenon Tube Bundle Cascade Product Concentration During Draw-off.

Calculations were made for the tube bundle cascade with stage 5 split into single-column stages. The cascade configuration would then be 6-5-5-4-1-1-1-1. With this eight-stage configuration the equilibrium time to obtain $10 \%$ xenon- 124 would be approximately 40 days. With the six-stage system equilibrium time for $10 \%$ xenon- 124 would be about 60 days. The draw-off rate for the eight-stage system was calculated to be approximately $28 \mathrm{ml} /$ day to obtain $10 \%$ xenon- 124 .

\section{THERMAL DIFFUSION RESEARCH}

Transport Coefficients The recent discovery of a diffusion barrier in the top of column Elo (see Table I of MLM- 1299) has prompted a reassessment of experimental flow data for $\mathrm{Ne}^{20}-\mathrm{Ne}^{22}$ separation taken

6MLM-1299, P. 30.

14 
previously for column E5.' It appears quite lıkely that a sımılar, but smaller, barrıer is present in this column; therefore, a new series of flow experiments is being run.

Before the flow experiments were started, the measurements of the statıc separation as a function of pressure were repeated to assure that the recent installation of a new wire had not materially altered the behavior of the column. The results of the static measurements are shown in Figure 6 , along with the results of two previous runs in September 1964 and July 1965, each with a different wire. The two theoretical curves are calculated for a wire temperature of $820^{\circ} \mathrm{C}$ from the Jones and Furry ${ }^{8}$ theory with Lennard-Jones shape factors. The thermal diffusion factor of 0.0227 was interpolated from Watson's data ${ }^{9}$ and the 0.0240 figure is taken from recent measurements with column EI. ${ }^{10}$

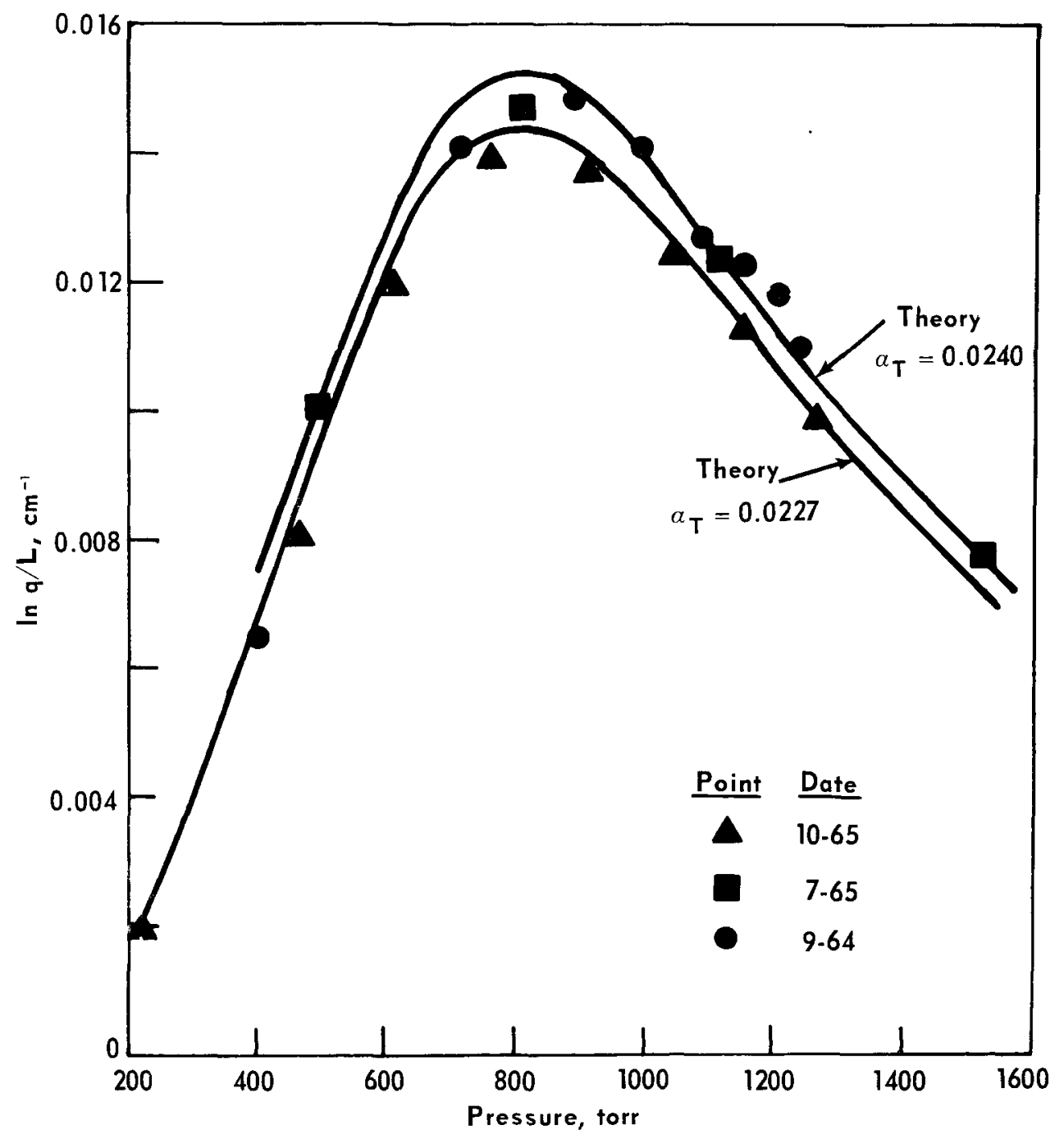

Figure 6. Static Separation Factor as a Function of Pressure for $\mathrm{Ne}^{20}-\mathrm{Ne}^{22}$ in Column E5.

$\overline{7 M L M-1238, p .} 29$.

${ }^{8}$ R. C. Jones and W. H. Furry, Revs. Modern Phys., 18, 151 (1946).

${ }^{9}$ W. W. Wats on, et al., Z. Naturforsch., 18a, 242 (1963).

$10 M L M-1300$, p. 19. 
For the flow experiments the column is being operated in a way similar to that reported for column EI last month ( $1 . e .$, the full length of the column is not used). The experiments are being done on a $152-\mathrm{cm}$ section of the $183-\mathrm{cm}$ column.

The transport coefficient $H^{\prime}$ for $\mathrm{He}^{3}-\mathrm{He}^{4}$ separation in column $\mathrm{E} 4$ was measured using flow data at a pressure of 1100 torr. Dimensions and temperatures for column E4 are given in Table 6 . The apparatus used is shown in Figure 7. Gas was circulated through the bottom of the column at 10 liters $/ \mathrm{min}$ and a measured flow rate was maintained from the column $4 \mathrm{ft}$ above this point. The flow rate was determined by measuring the rate of pressure increase in a calıbrated vessel. A constant pressure of $1100 \pm 2$ torr was maintained in the column using an absolute pressure regulator. The column was operated for $48 \mathrm{hr}$ at constant pressure and flow rate. Samples were then taken at sample ports $A$ and $C$ at the bottom of the column. Port $C$ was used instead of port $D$ to elıminate end effects caused by the $101 / 1$ ter $/ \mathrm{min}$ feed circulation loop at the bottom of the column. The helium-3 concentration varied along the length of the 12 -ft column, causing var Iation in the values of the column transport coefficients. A 3 - $\mathrm{ft}$ column was used to assure, for practical purposes, a constant helium- 3 concentration along the length of column. The average concentration of helium-3 in the 3-ft section was $3 \%$. It was thus possible to obtain an accur ate value of $H^{\prime}$ for $3 \% \mathrm{He}^{3}-\mathrm{He}^{4}$ separation. Samples were taken for various flow rates, and the data are plotted in Figure 8 as the natural log of the separation factor as a function of flow. From these data $H^{\prime}$ was calculated and the results are given in Table 7. Values of $K_{c}{ }^{\prime}$ and $K_{d}$ are also given in the table. These values were obtained from the ratios $K_{c} / H^{\prime}$ and $K_{d} / H^{\prime}$ which were determıned earlier in statıc experıments."

Table 6

\section{DIMENSIONS AND OPERATING CONDITIONS OF EXPERIMENTAL THERMAL DIFFUSION COLUMNS}

\begin{tabular}{ccccccc} 
Column & $\begin{array}{c}\text { Length } \\
(\mathrm{cm})\end{array}$ & $\begin{array}{c}\text { Cold Wall } \\
\text { Radius } \\
(\mathrm{cm})\end{array}$ & $\begin{array}{c}\text { Hot Wall } \\
\text { Radius } \\
(\mathrm{cm})\end{array}$ & $\begin{array}{c}\text { Cold Wall } \\
\text { Temp. } \\
\left({ }^{\circ} \mathrm{C}\right)\end{array}$ & $\begin{array}{c}\text { Hot Wall } \\
\text { Temp. } \\
\left({ }^{\circ} \mathrm{C}\right)\end{array}$ & Gas \\
\hline E4 & 366 & 205 & 00794 & 15 & 800 & $\mathrm{He}^{3}-\mathrm{He}^{4}$ \\
E5 & 183 & 0943 & 00804 & 15 & 820 & $\mathrm{Ne}^{20}-\mathrm{Ne}^{22}$
\end{tabular}

Table 7

THERMAL DIFFUSION COLUMN TRANSPORT COEFFICIENTS FOR SEPARATION OF $3 \% \mathrm{He}^{3}-\mathrm{He}^{4}$ AT $800^{\circ} \mathrm{C}$ AND IIOO TORR PRESSURE

\begin{tabular}{cll} 
Parameter & Measured & Predicted \\
\hline$H^{\prime}\left(\mathrm{g} \mathrm{sec}^{-1} \mathrm{~atm}^{-2}\right)$ & $177 \times 10^{-4}$ & $178 \times 10^{-4}$ \\
$K_{c}^{\prime}\left(\mathrm{g}-\mathrm{cm} \mathrm{sec}^{-1} \mathrm{~atm}^{-4}\right)$ & $619 \times 10^{-3}$ & $769 \times 10^{-3}$ \\
$K_{d}(\mathrm{~g}-\mathrm{cm} \mathrm{sec}$ & & $452 \times 10^{-3}$
\end{tabular}

$\overline{11 M L M-1227, p} \cdot 23$. 


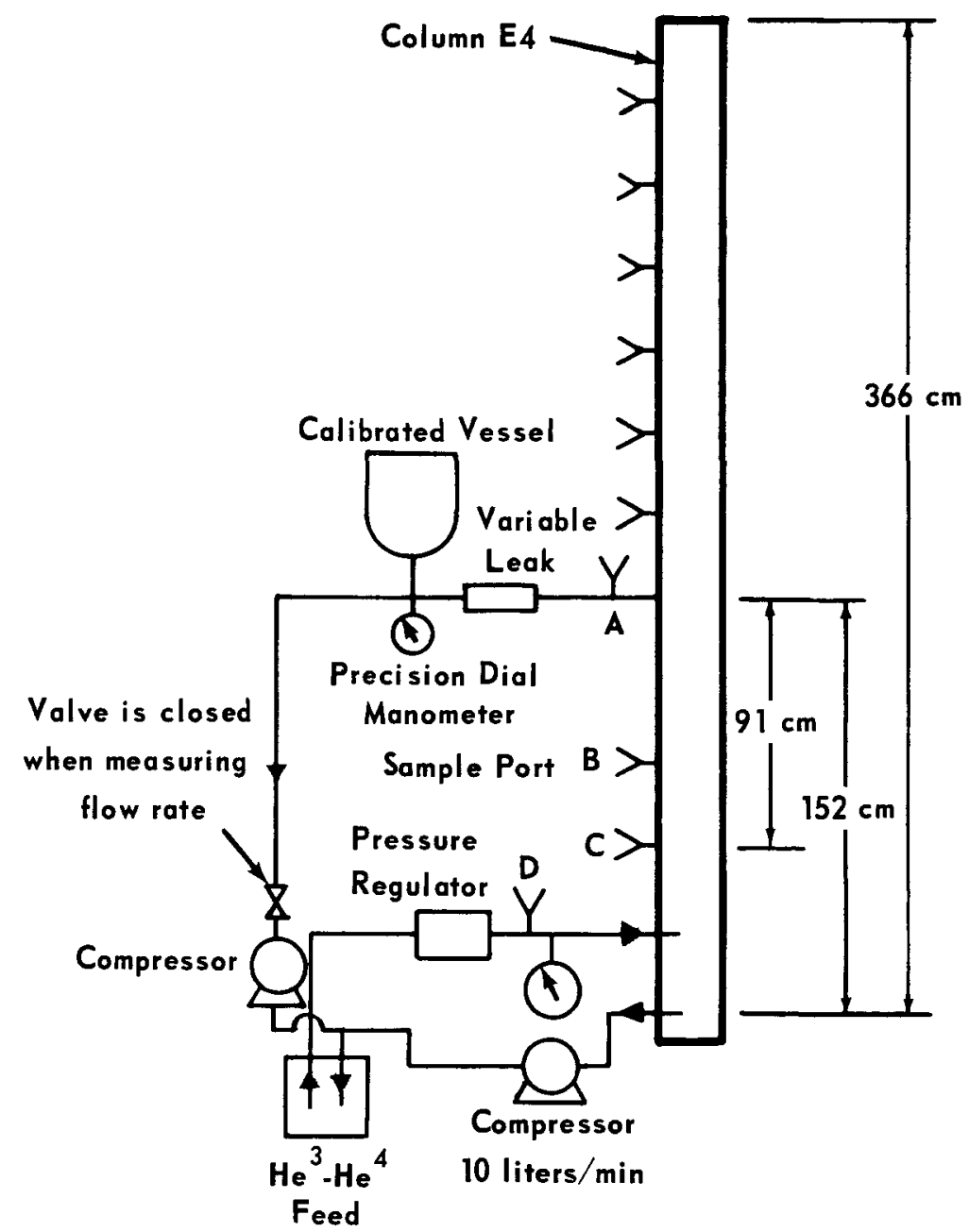

Figure 7. Schematic Diagram of the Apparatus Used to Measure $H^{\prime}$ for a $3 \% \mathrm{He}^{3}-\mathrm{He}^{4}$ Separation.

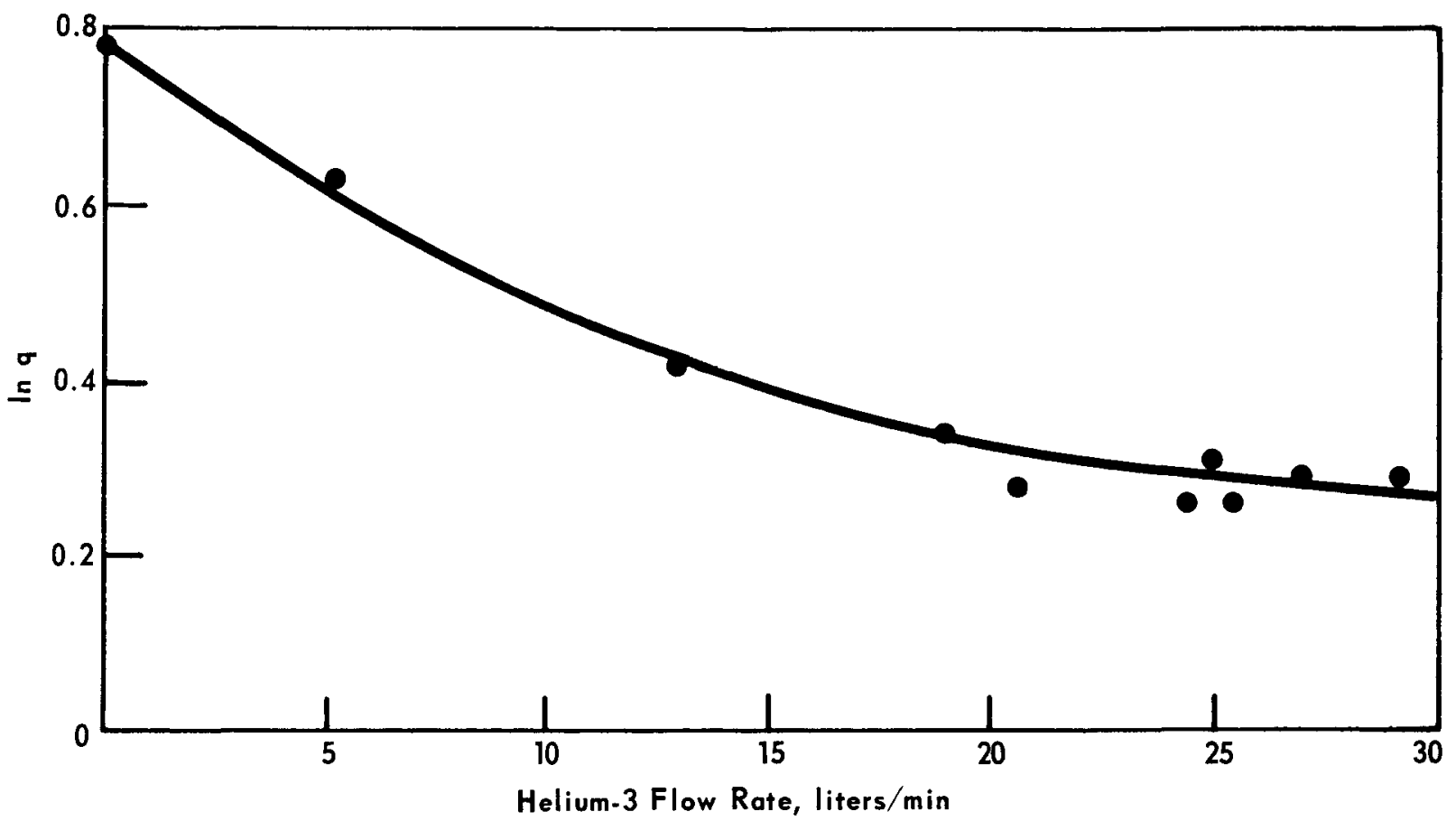

Figure 8. Separation as a Function of Flow Rate for the $\mathrm{He}^{3}-\mathrm{He}^{4}$ Separation in the 3-ft Section of Column E4. 
The theoretical values of the coefficients given in Table 7 were calculated from Lennard-Jones shape factors. A value of 0.0618 was assumed for the thermal diffusion factor at $288^{\circ} \mathrm{K}$ and a helium- 3 concentration of $3 \%$.

The experimental value of $H^{\prime}$ agrees well with the theoretical one; however, both experimental remixing coefficients deviate from theory. The directions and magnitudes of the deviations suggest that the diffusion coefficient used in the theoretical calculation may be incorrect, or that the temperature dependence of the diffusion coefficient for $\mathrm{He}^{3}-\mathrm{He}^{4}$ may not be adequately represented by the Lennard-Jones model in the high-temperature region.

Transport Properties Thermal diffusion ratios for binary isotopic and unlike gas mixtures are presently being measured in a 20-tube Trennschaukel. Experimental uncertainties in this work are expected to be reduced to less than 5\%. If this can be accomplished, then the experimental thermal diffusion measurements can be used as a sensitive test of the intermolecular potential function.

The general expression for the thermal diffusion ratio is quite complicated. It is both concentration- and temperature-dependent, the latter arising from the temperature dependence of the collision integrals. The $m$ th approximation of the thermal diffusion ratio for a binary mixture, which is most conveniently written in the determinant notation of Chapman and Cowling, ${ }^{12}$ is

$$
\left[k_{T}\right]_{m}=\frac{5}{2} \frac{x_{1} D_{0}(m)\left(\frac{M_{1}+M_{2}}{2 M_{1}}\right)^{1 / 2}+x_{2} D_{0-1}(m)\left(\frac{M_{1}+M_{2}}{2 M_{2}}\right)^{1 / 2}}{D_{00}{ }^{(m)}}
$$

where $x_{1}$ and $x_{2}$ are the mole fractions of the two components of masses $M_{1}$ and $M_{2}$. The $D^{(m)}$ are determinants whose elements are functions of the collision integrals and molecular weights. Expressions for these elernents up to and including $m=3$ have been derived by Mason and are presented elsewhere. 13,14 in this work Mason has also shown that Equation I can be simplified if one has a binary system of heavy isotopes. In this case one has

$$
\left[k_{T}\right]_{m \text { (heavy) }}=\left[k_{T}^{*}\right]_{m}\left(\frac{M_{1}-M_{2}}{M_{1}+M_{2}}\right) x_{1} x_{2}
$$

where $\left[k_{T}^{*}\right]_{m}$ is a reduced thermal diffusion ratio dependent only upon the reduced temperature $T^{*}$.

In order to test the accuracy of the various approximations, $\left[k_{T}\right]_{m}$ and $\left[k_{T}\right]_{m}$ (heavy) were calculated for $m=1,2$ for $\mathrm{He}^{3}-\mathrm{He}^{4}$ mixtures of different compositions. In addition, it was desired to test the sensitivity of this calculation to the intermolecular potential so the entire set of calculations was carried out for two values of the parameter, $a$, which appears in the Modified Buckingham Potential. The results are shown in Figures 9-14.

\footnotetext{
125. Chapman and T. G. Cowling. The Mathematical Theory of Non-Uniform Gases, London, Cambridge University Press, 1952.

${ }^{13}$ E. A. Mason, J. Chem. Phys., 22, 169-186 (1954).

14E. A. Mason, J. Chem. Phys., 27, 75-84 (1957).
} 


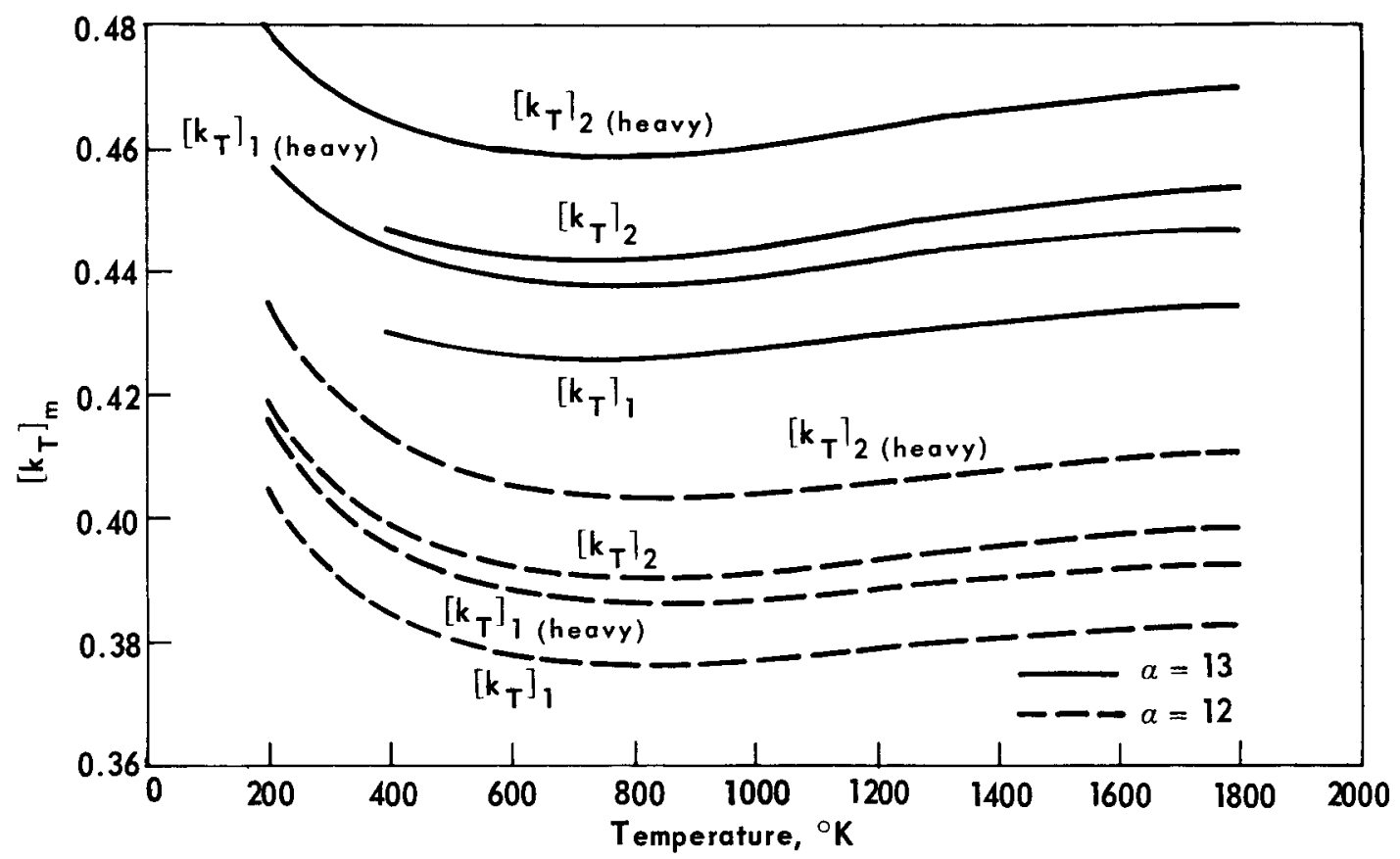

Figure 9. Thermal Diffusion Ratios for $0.00001 \mathrm{He}^{3}-0.99999 \mathrm{He}^{4}$.

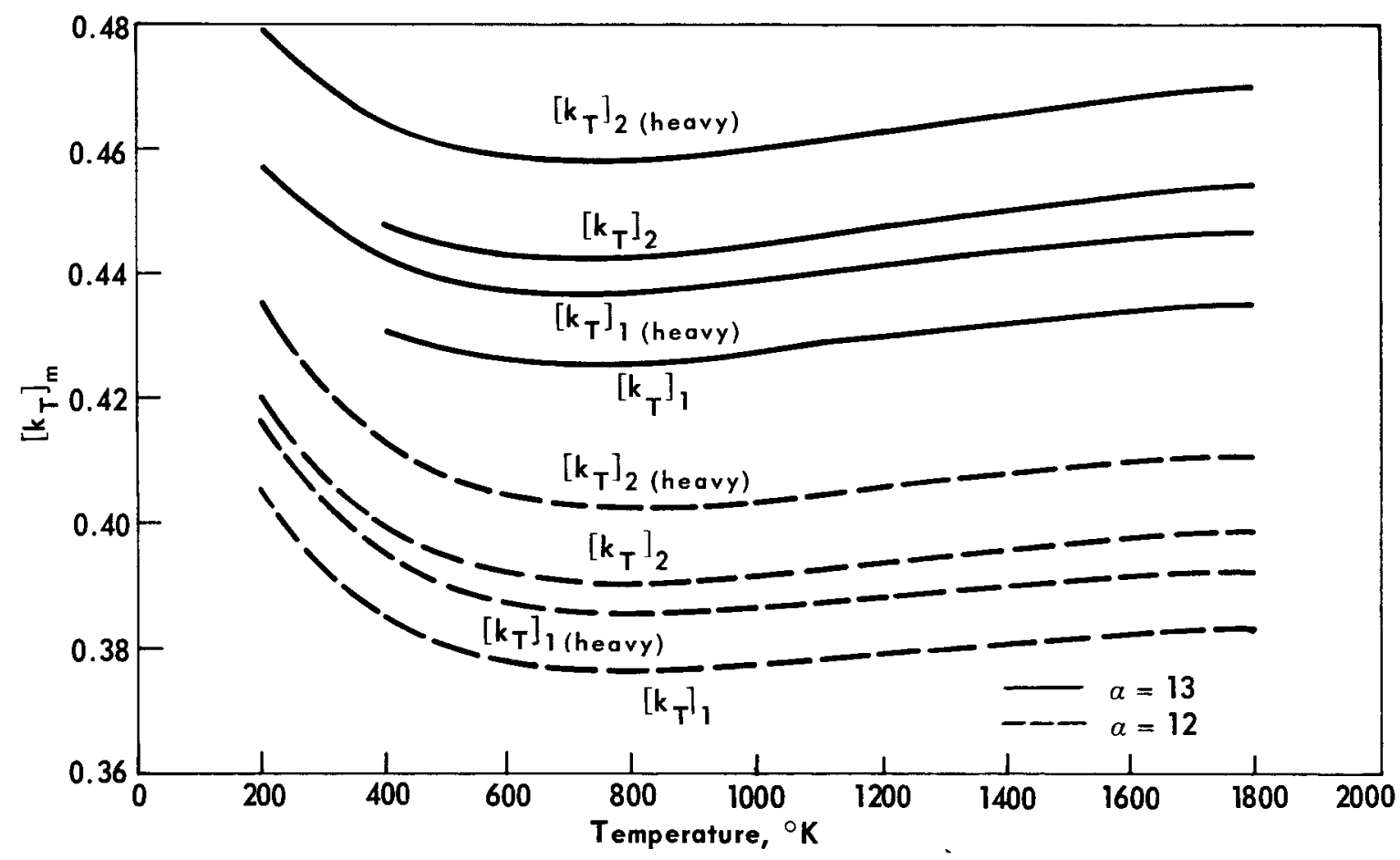

Figure 10. Thermal Diffusion Ratios for $0.05 \mathrm{He}^{3}-0.95 \mathrm{He}^{4}$. 


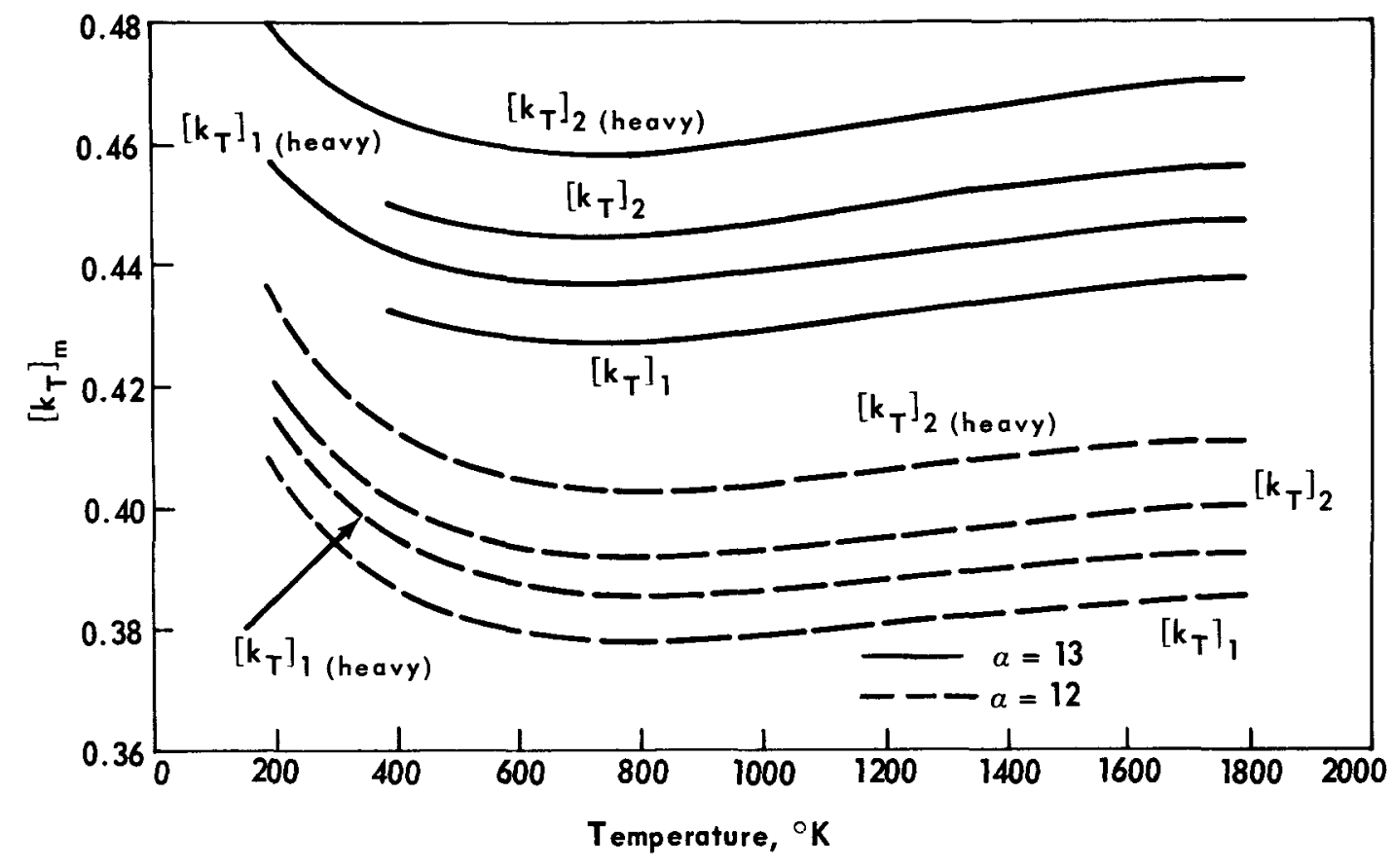

Figure 11. Thermal Diffusion Ratios for $0.1 \mathrm{He}^{3}-0.9 \mathrm{He}^{4}$.

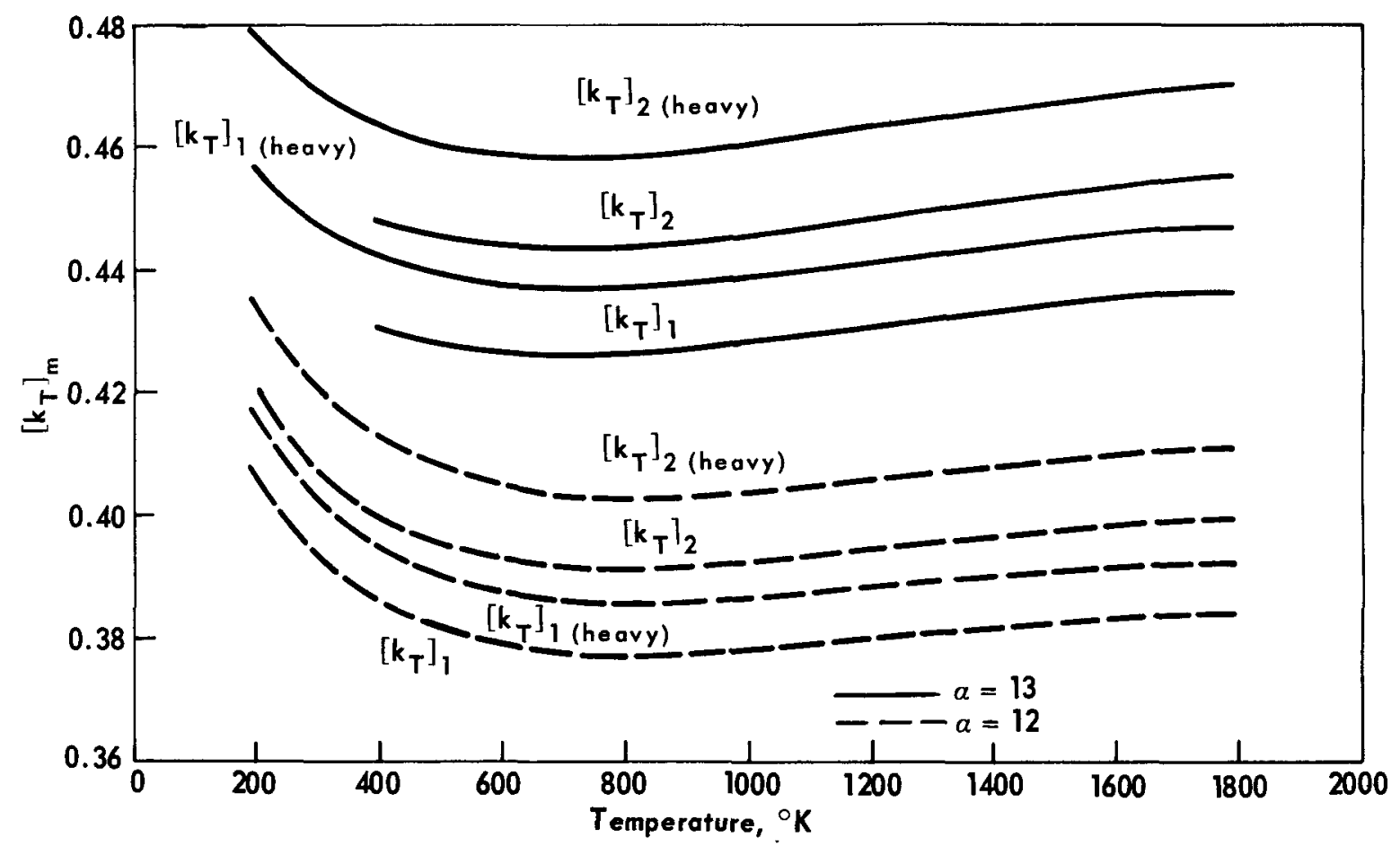

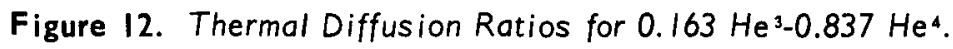




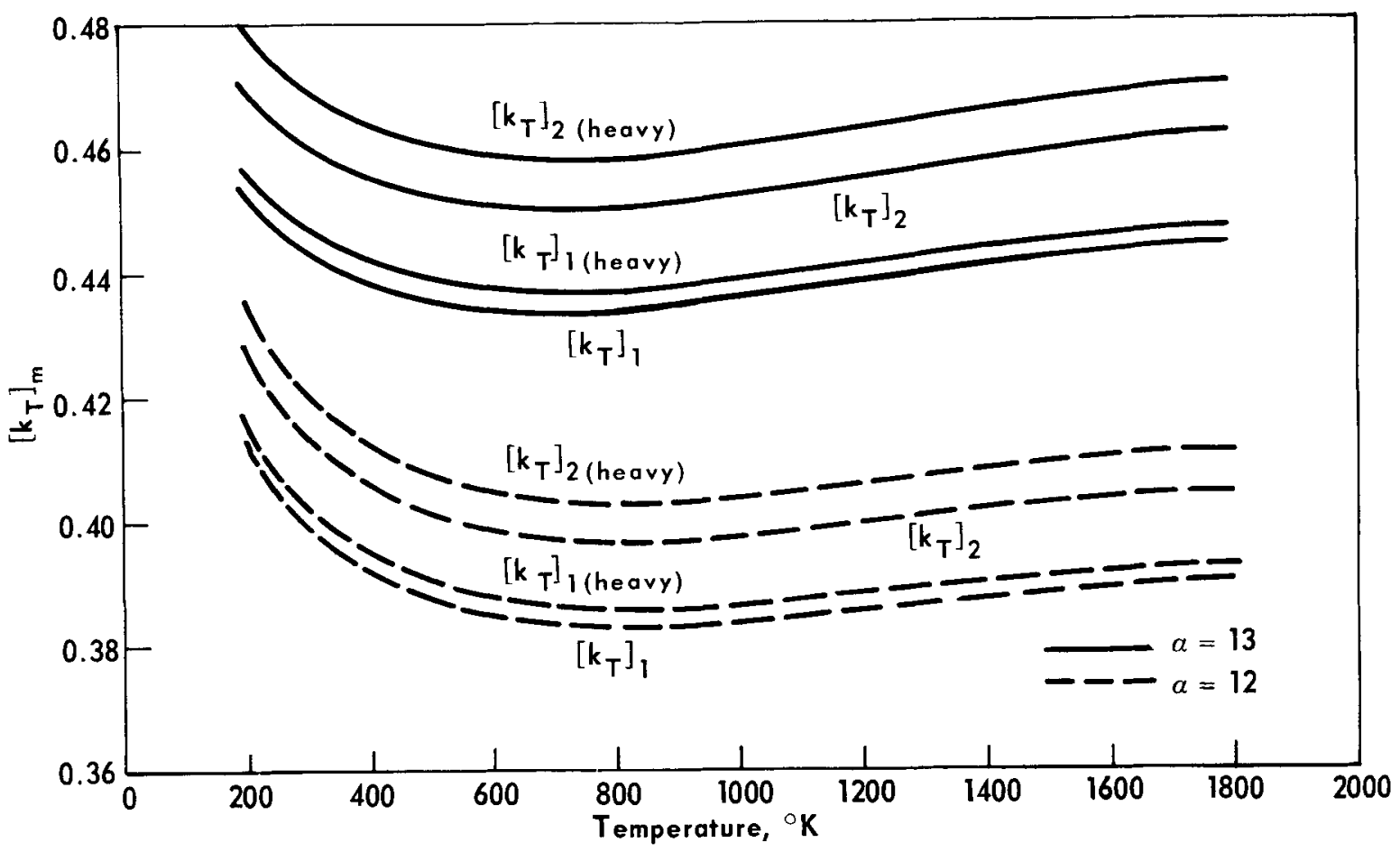

Figure 13. Thermal Diffusion Ratios for $0.5 \mathrm{He}^{3}-0.5 \mathrm{He}^{4}$.

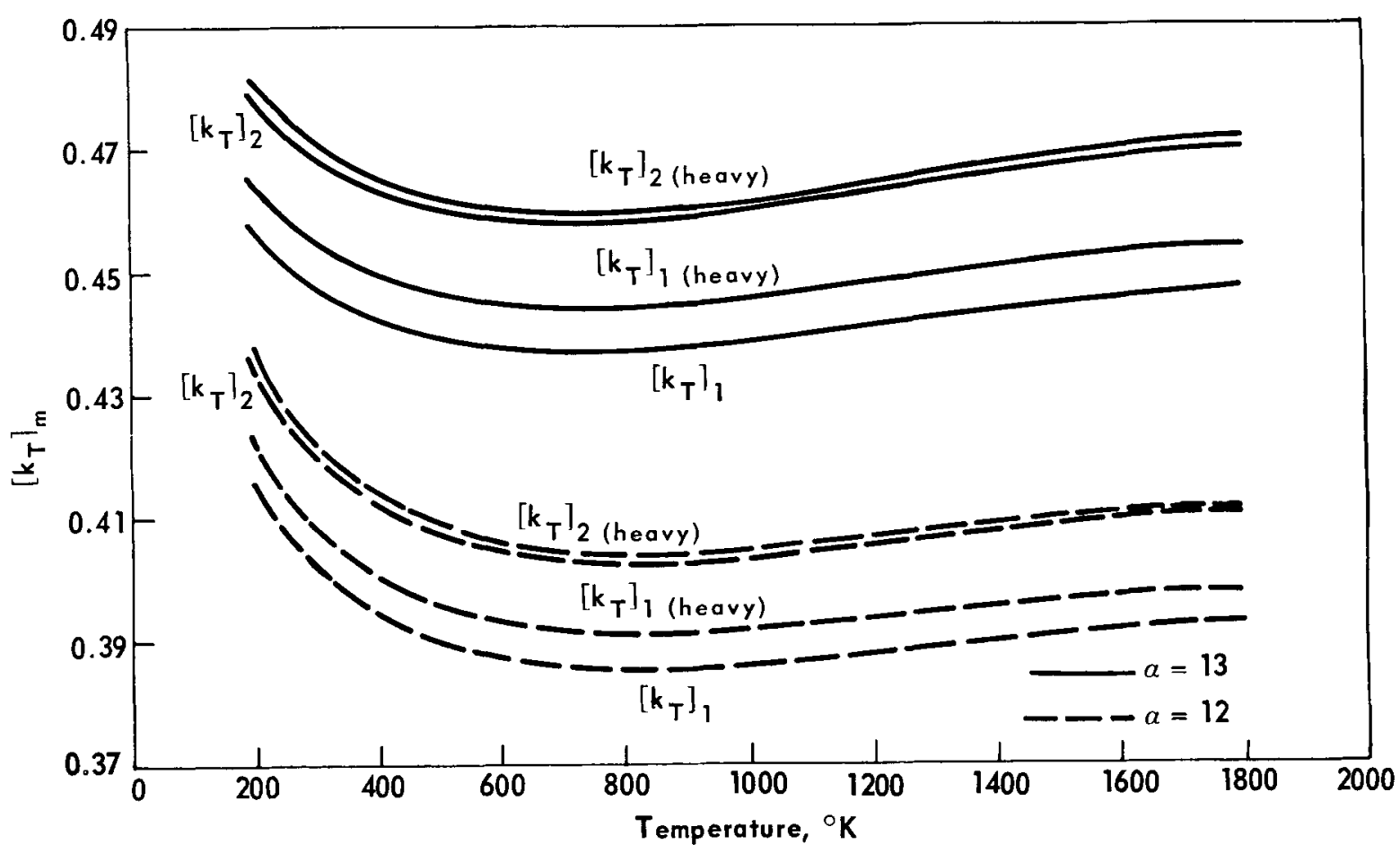

Figure 14. Thermal Diffusion Ratios for $0.99999 \mathrm{He}^{3}-0.00001 \mathrm{He}^{4}$. 
It is immediately apparent that the calculation is very sensitive to the potential parameters (I.e.. less than $10 \%$ change in $a$ gives rise to greater than $10 \%$ variation in $\left[k_{T}\right]_{m}$ in all cases). In addition, if $\left[k_{T}\right]_{2}$ is assumed to represent the correct value, both the complete first approximation and the heavy isotope second approximation differ from this as much as $5 \%$ in some cases. The agreement between $\left[k_{T}\right]_{1}(h e a v y)$ and $\left[k_{T} l_{2}\right.$ is most likely coincidental

One may conclude, therefore, that the "correctness" of the repulsive part of the intermolecular potential may be determıned to very roughly the same degree as the experımental uncertaınty in the Trennschaukel measurements. In addition, as the experımental results become more reliable one must examıne more closely whether a given approximation is adequate for comparison with experiment. In view of the large discrepancy among the various approximations, the rate of convergence is not at all obvious and calculation of the third approximation will be necessary.

There is some indication that the intermolecular forces, or more specifically the interatomic forces, for helıum-4 are different from those for helıum-3 or that there are rather large errors in the theoretical calculations of the transport propertıes of helıum-3. ${ }^{15}$ In an effort to obtaın more information concerning the interatomic forces, the spectroscopıc data for the $\mathrm{He}_{2}$ molecule were examıned. ${ }^{6,17}$ Usıng the standard formulae for the relations between the molecular constants for isotopic molecules, the spectra of $\mathrm{He}_{2}^{3}$ and $\mathrm{He}_{2}^{4} g i v e$ no indication of a difference in the interatomic forces.

The formulae referred to above were derived by Dunham ${ }^{18}$ and are presented by Herzberg. ${ }^{19}$ These formulae, which relate the molecular constants of one molecule to those of an is otopically substituted molecule, are:

$$
\begin{aligned}
& \omega_{e}{ }^{\imath}=\rho \omega_{e} \\
& \omega_{e} x_{e}{ }^{\imath}=\rho^{2} \omega_{e} x_{e} \\
& \beta_{e}{ }^{\imath}=\rho^{2} \beta_{e} \\
& a_{e}{ }^{\imath}=\rho^{3} a_{e}
\end{aligned}
$$

where $\omega_{e}$ and $\omega_{e} x_{e}$ are the vibrational constants, $\beta_{e}$ and $\alpha_{e}$ are the rotational constants, and $\rho$ is the square root of the ratıo of the reduced masses.

The above expressions were used to calculate the molecular constants of the $a^{3} \Sigma^{+} \mu$ state of He from experimental molecular constants of $\mathrm{He}_{2}^{4}$ for the same state. This is the lowest-lyıng stable electronıc state for $\mathrm{He}_{2}$ and there are suitable data avallable. ${ }^{16,17}$

\footnotetext{
15. Weissman, Bull. Am. Phys. Soc., 10,735 (1965).

${ }^{16} \mathrm{M} S \mathrm{G}$ Ginter, J. Chem. Phys., 42, 561 (1965).

17G. H. Dieke and E. S. Robinson, Phys. Rev., 80, I-5 (1950).

${ }^{18} \mathrm{~J}$. S. Dunham, Phys. Rev., 41, 721 (1932).

${ }^{19} \mathrm{G}$. Herzberg, Spectra of Diatomic Molecules, 2nd ed., New York, D. Van Nostrand Company, Inc., I950, p. 145 .
} 
Table 8 gives the observed and calculated values of the molecular constants for this state. The agreement between the two sets of values is a strong indication that the potential energy curves for the two molecules are the same

Table 8

MOLECULAR CONSTANTS FOR $a^{3} \Sigma^{+} \mu \mathrm{He}_{2}^{3}$

\begin{tabular}{lccc} 
Constant & $\begin{array}{c}\text { Observed } \\
\left(\mathrm{cm}^{-1}\right)\end{array}$ & $\begin{array}{c}\text { From He} \\
\left(\mathrm{cm}^{-1}\right)\end{array}$ & $\begin{array}{c}\text { Difference } \\
(\%)\end{array}$ \\
\hline$\omega_{\mathrm{e}}$ & 208565 & 208502 & 003 \\
$\omega_{\mathrm{e}} \mathrm{e}_{\mathrm{e}}$ & 5161 & 5183 & 04 \\
$\beta_{\mathrm{e}}$ & 10222 & 10232 & 01 \\
$\alpha_{\mathrm{e}}$ & 03727 & 03465 & 76
\end{tabular}

The fact that the spectroscopic data on the $a^{3} \Sigma^{+} \mu$ state of $\mathrm{He}_{2}$ are consistent for both isotopes does not prove unequivocally that forces are also identical when two ground state atoms approach each other This molecular state corresponds to one helium in the $1 s^{2}$ iS ground state and one atom in the $152 s{ }^{3} S$ excited state However, the indication is now that the theoretical calculations of the transport properties of helıum3 need to be reexamıned

\section{HELIUM RESEARCH}

Vapor Pressure Thermometry Thermomolecular pressure corrections are necessary for precise vapor pressure thermometry In the experimental and theoretical investigation of these corrections, it has become clear that the effect depends on the material of a tube surface In a previous report ${ }^{20}$ an equation simılar to the Weber-Schmidt expression for thermomolecular pressure has been developed In this development, one of the parameters that appears is the fraction. $f$, of molecules which give up all their tangential momentum in collisions with the tube wall It will be shown that a varıation of this parameter can account for the difference between measurements using staınless steel tubes and the thermomolecular pressure given by the Weber-Schmidt equation

Recallıng the form of the equations from Reference 20 , the differential pressure change as a function of temperature and mean free path is given by ${ }^{21}$

$$
\frac{d P}{d T}-\frac{1}{2} \frac{P}{T}\left\{\frac{\pi}{24} \frac{\gamma}{K} \frac{1}{1+\frac{\gamma \beta}{K}} \frac{a^{2}}{\lambda^{2}}\left[1+4 K\left(\frac{1+2 \frac{\gamma \beta}{K}}{1+\frac{\gamma \beta}{K}}\right) \frac{\lambda}{a}\right]+\left[\frac{\frac{1}{4 K}\left[1+\frac{\frac{2 \pi}{3} K \gamma\left(\frac{\gamma \beta}{K}\right)^{2}}{\left(1+\frac{\gamma \beta}{K}\right)^{2}}\right] \frac{a}{\lambda}}{1+\frac{1}{4 K}\left(1+\frac{\gamma \beta}{K}\right) \frac{a}{\lambda}}\right]\right\}^{-1}
$$

\footnotetext{
$20 M L M-1287$ p 24

${ }^{2}$ E quations 7 and 9 above as given in MLM-1287 are incorrect, the correct forms are given here
} 
where now in terms of $K, \gamma$, and $\beta$, the Weber-Schmidt constants are: ${ }^{21}$

$$
\begin{aligned}
& K_{1}=\beta+\frac{K}{\gamma} \\
& g=\frac{1}{4 K}\left[1+\frac{\frac{2 \pi}{3} K \gamma\left(\frac{\gamma \beta}{K}\right)^{2}}{\left(1+\frac{\gamma \beta}{K}\right)^{2}}\right] \\
& K_{2}=K\left(\frac{1+2 \gamma \beta / K}{1+\gamma \beta / K}\right) \\
& h=\frac{1}{4 K}\left(1+\frac{\gamma \beta}{K}\right)
\end{aligned}
$$

It is helpful here to review the physical significance of $K, \gamma$ and $\beta . K=(2-f) / f$ is a measure of the fraction of molecules reflected diffusely from the tube wall. The term $\gamma=9 \alpha / 4 \beta_{f}^{2}$ is a measure of the deviation from the Maxwellian distribution of the molecules making their last collision with the wall. There is also a geometry factor $\alpha$ in $\gamma \cdot \beta=\beta_{l} \beta_{v}$ is a measure of the deviation from the Maxwellian distribution of the molecules making their last collision in the gas.

Equation 7 has been solved to obtain the pressure difference between two fixed temperatures for many different values of $K, \gamma$ and $\beta$. A preliminary comparison with the experimental results has been made. Figure 15 shows the measured thermomolecular pressure difference in two stainless steel tubes (data points). The curve shows the result for the same radii tubes calculated from the original Weber-Schmidt equation. There is clear disagreement. Figure 16 shows the same data with two superimposed curves. These curves were calculated from Equation 7 with the same values of $\gamma$ and $\beta$ but different values of $K$. Curve (1) which fits the Mound data is for $K=1.0, \gamma=2.4$ and $\beta=1.6$. The particular values of $\gamma$ and $\beta$ reflect the fact that the velocity distribution function of the gas is not Maxwellian. The determination of theoretical values for $\gamma$ and $\beta$ is a problem of much greater difficulty than the one treated here. It is clear that they may be functions of $K$. Here $\gamma$ and $\beta$ are assumed to be independent of $K$.

Turning to the effect of varying $K$ in Figure 16, it is seen that the data and the Weber-Schmidt curve are fit reasonably well with just a variation of $K$. A value of $K=1$ means $f=1$ and $K=1.25$ means $f=0.9$, where $f$ is the fraction of molecules that give up all their tangential momentum in collisions with the wall. At this point it is of interest to note two facts: (1) the Weber-Schmidt data were taken on glass tubes, and (2) independent measurements of $f$ for several gases on different surfaces have been made by Millikan. ${ }^{22}$ He finds $f=1.0$ for air or carbon dioxide on polished metal surfaces and $f=0.89$ for air on glass. The variation in $f$ to fit the thermomolecular pressure data is of the same order and sense.

$\overline{22 R . A . ~ M i l l i k a n, ~ P h y s . ~ R e v ., ~} 21,217$ (1923). 


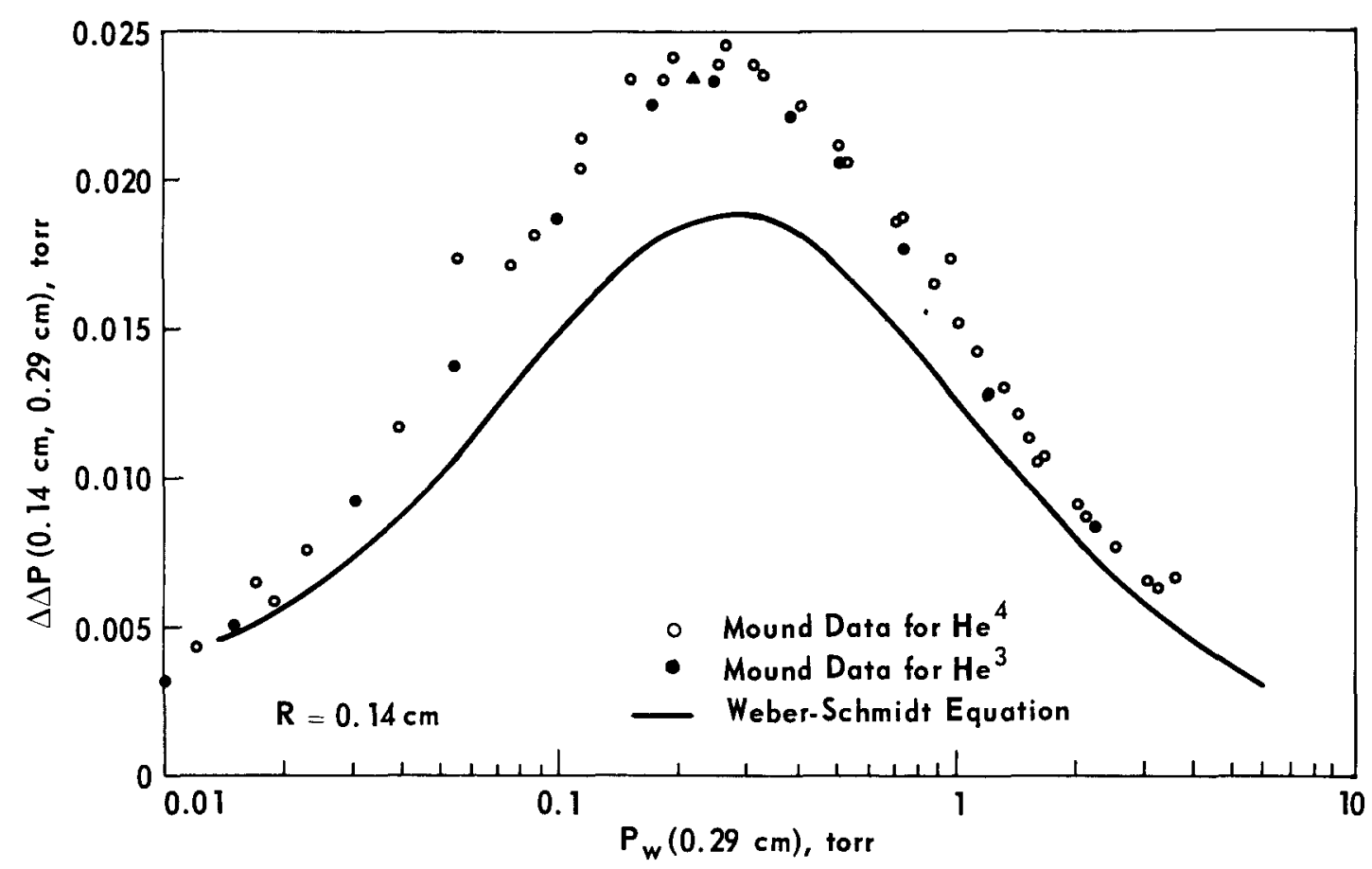

Figure 15. Measured Thermomolecular Pressure Difference in Two Stainless Steel Tubes.

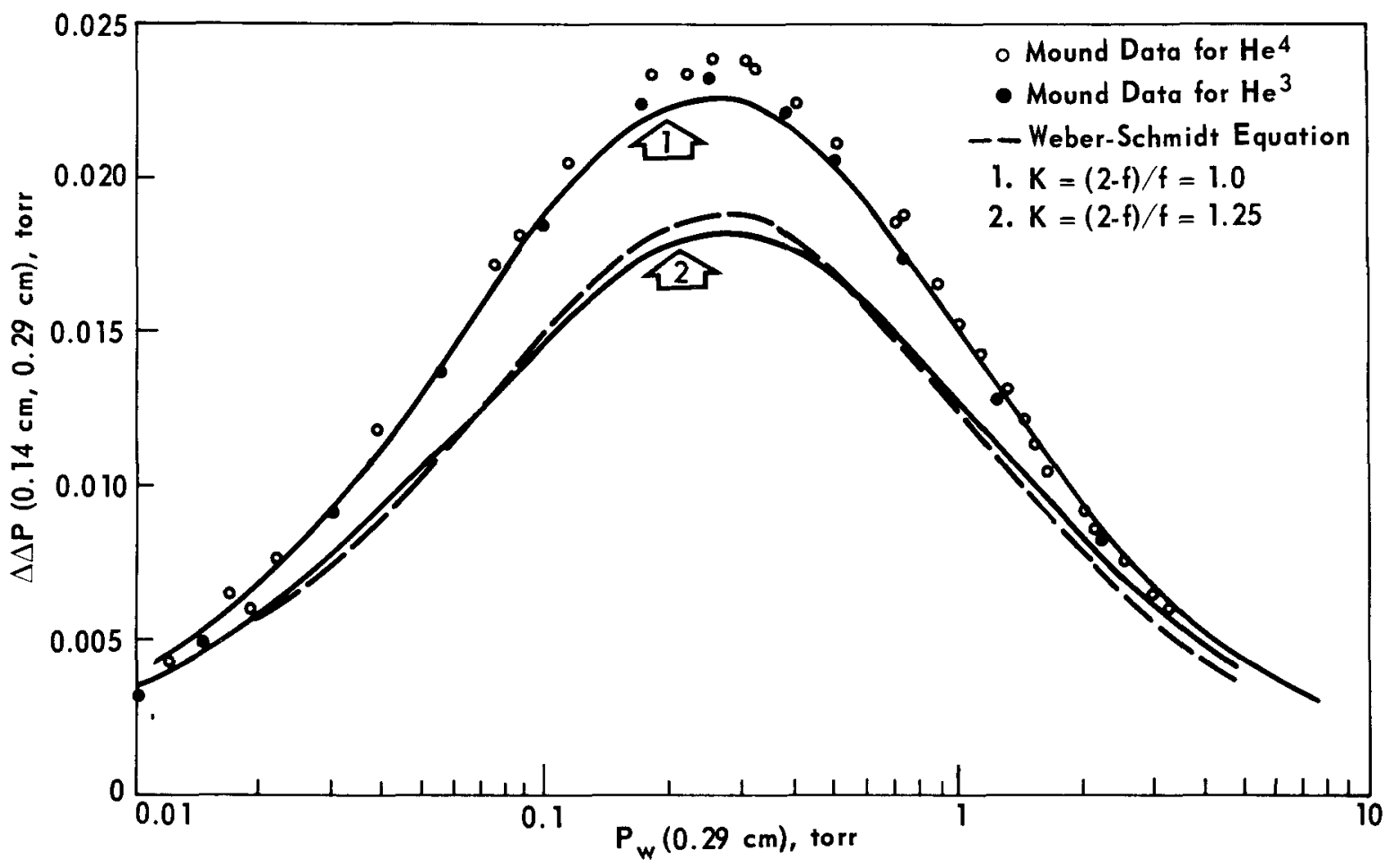

Figure 16. Curves Using the Same Data as in Figure 15 but Different Values of $K$. 
In view of these results an apparatus with Pyrex tubes has been built for thermomolecular pressure measurements. The configuration is slightly different from the stainless tube apparatus. The large-diameter glass tube is $2 \mathrm{in.}$ in diameter rather than $0.25 \mathrm{in}$. as for the stainless steel tube. Thus, what is measured over a large pressure range is $\Delta P$ rather than $\Delta \Delta P=\Delta P_{1}-\Delta P_{2}$. Preliminary measurements with the glass tubes are shown in Figure 17. The data in this figure lie below the Weber-Schmidt curve. The solid curve is $\Delta P$ for the small tube. The dashed line represents the effect of the 2 -in. tube. Preliminary calculations indicate that a value of $f \approx 0.85$ fits these data.

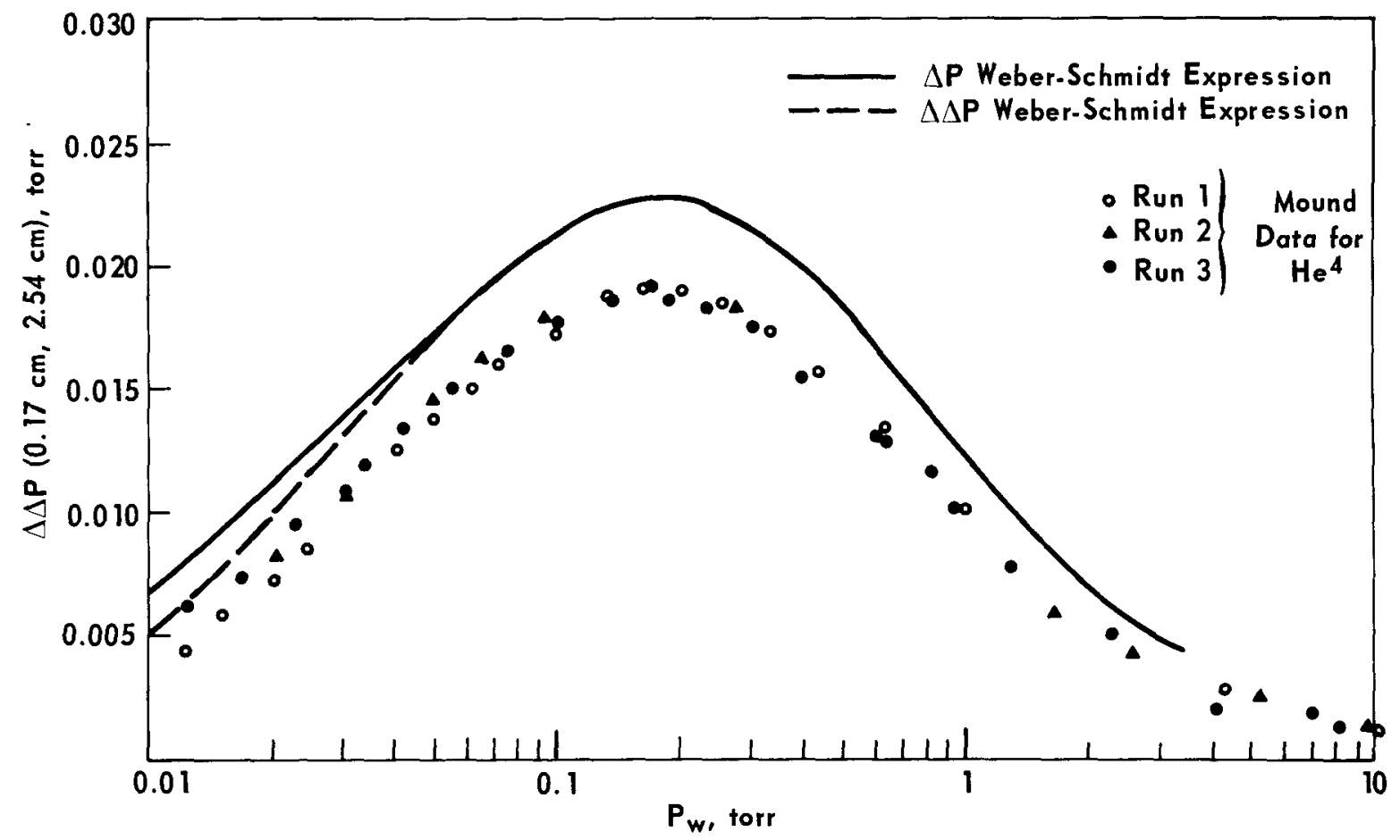

Figure 17. Preliminary Measurements with Glass Tubes. 